\title{
SOCIO-DEMOGRAPHIC PROFILE OF HIV PATIENTS ATTENDING ART CENTRE, VIMS: A HOSPITAL BASED DECRIPTIVE STUDY
}

\author{
Ramesh. K, Sangeetha Gandhi, Vishwas Rao, Anusha. C. P, Spoorthi Prakash.
}

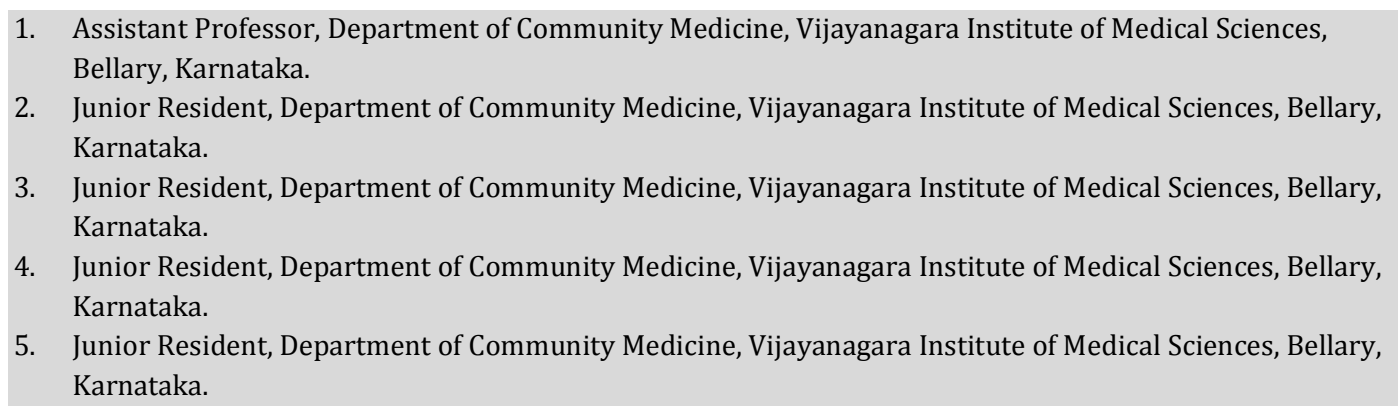

\section{CORRESPONDING AUTHOR}

Dr. Ramesh. K. MBBS, MD,

Assistant Professor, Department of Community Medicine,

Vijayanagara Institute of Medical Sciences (VIMS),

Bellary -583104, Karnataka,

E-mail: ramspsm@yahoo.co.in,

Ph: 00919481181291

ABSTRACT: BACKGROUND: The human immunodeficiency virus (HIV) infection is a global pandemic.HIV continues to be a burden globally and presents serious public health problems in the developing countries, especially in India. According to the UNAIDS and World Health Organization (WHO) reports of November 2010, there are approximately 33.3 million people living with HIV/Acquired immunodeficiency syndrome (AIDS) worldwide, with a global prevalence of $0.8 \%$. It is now the leading cause of adult deaths in the world due to infectious diseases. HIV has become the first truly international epidemic easily crossing the oceans \& borders. METHODOLOGY: A case-series study was conducted among HIV positive patients coming to the ART centre for seeking treatment at ART Centre, Vijayanagara Institute of Medical Sciences Bellary, Karnataka from March 2011 to September 2011. The sample size of the study was 500 and consecutive sampling technique is used. Permission from respective authorities and written consent from study participants was obtained. Data was collected using a pre tested semi structured questionnaire. Data was analyzed using SPSS 15.0. RESULTS: The study subjects included both males (54\%) and females (46\%). The educational status is less than primary schooling in $88 \%$ of study subjects and $90 \%$ are married. Hetero sexual route of transmission was most common and only $16.1 \%$ of study subjects used contraceptives. CONCLUSION: Both males and females were equally infected with HIV and productive age group is more commonly affected. Use of contraception is very low.

KEY WORDS: HIV, ART, Mode of transmission

INTRODUCTION: Since the recognition of AIDS pandemic, many efforts have been concentrated on the prevention of HIV transmission'1. In INDIA as stated by NACO people living with AIDS for the year 2009 estimates 23.1 lakhs which equates to a prevalence of $0.3 \%$. Well this may seem low compared to large population of our country, but a mere $0.1 \%$ increase in HIV prevalence would increase the estimated no of people living with HIV by over half a million!!!!2. Since India 
has emerged as a major player in the global HIV epidemic, and, the lack of information on knowledge, perceptions, and behaviors regarding HIV risk and preventive behaviors among Indian adolescents is alarming!!3.

Nowadays, interventions to stem the spread of the Human immunodeficiency virus (HIV) throughout the world are as varied as the contexts in which we find them. Not only is the HIV epidemic dynamic in terms of treatment options, Prevention strategies and disease progression, but sexual Behavior which remains the primary target of AIDS Prevention efforts worldwide, is widely diverse and deeply embedded in individual desires, social and cultural Relationships, and environmental and economic Processes. This makes prevention of HIV, which could be an essentially simple task, enormously complex involving a Multiplicity of dimensions .To respond effectively to heterosexual acquired HIV infection, it is important to understand sexual behavior of persons infected with HIV that facilitate or protect against transmission ${ }^{4}$ Behavioral change has been responsible for the prevention successes to date. Strategies to modify risk behaviors need to remain a main priority for HIV prevention ${ }^{5}$. By behavioral strategies we mean an attempt to delay onset of first intercourse, decrease the number of sexual partners, increase the number of sexual acts that are protected, provide counseling and testing for HIV, encourage adherence to biomedical strategies preventing HIV transmission, decrease sharing of needles and syringes, and decrease substance use. Behavioral strategies to accomplish these goals can focus on individuals, couples, families, peer groups or networks, institutions, and entire communities ${ }^{5}$.

OBJECTIVE: To study the socio demographic profile of HIV patients

METHODOLOGY: A case-series (descriptive) study was conducted among HIV positive patients coming to the ART centre for seeking treatment at ART Centre, Vijayanagara Institute of Medical Sciences Bellary, Karnataka from March 2011 to September 2011. Totally 10,000 patients have registered and among them 5000 patients were on treatment at ART centre. Hence this study considered patients only who were on treatment. Totally 500 patients were included for the study. These 500 patients were selected based on non probability purposive sampling technique.

Data was collected using a pre designed semi structured questionnaire which contained information regarding socio demographic details and behavior. After obtaining written informed consent, data was collected by interview technique and after the data collection health education was given to patients on Prevention \& treatment of HIV. Patients who were seriously ill and those who did not give consent were excluded from the study

Data was entered in Microsoft excel and analyzed in SPSS 15.

RESULTS: Among 500 study subjects, $54 \%$ were males and $46 \%$ were females. More numbers of study subjects were in 30 - 39 years of age group (39\%) followed by $20-29$ years(32\%), 40 - 49 years $(25 \%)$ and more than 50 years $(4 \%)$. It was observed that majority of study subjects were between 20 to 39 years (71\%). Among males, more number of study subjects were in 30 39 years of age group(40.8\%) and whereas among females, more number of study subjects were in 20 - 29 years of age group(43.6\%) (Table 1)

Among 500 study subjects, $16.4 \%$ of them were not known how they might have acquired HIV infection but it was found that heterosexual route of transmission of HIV was more common among study subjects i.e. 83\%. Blood transfusion and inject able drug abuse contributed $0.60 \%$ collectively (Table.no. 2 ).

Journal of Evolution of Medical and Dental Sciences/Volume1/Issue5/November-2012Page-831 
Out the 500 subjects taken for our study $45 \%$ of them were illiterates, $43 \%$ of subjects had just primary education, $9 \%$ of subjects had high school education and $2 \%$ of them had completed their education till pre university level.

In our study about half of the study subjects were unskilled workers primarily daily wage workers followed by semi skilled and skilled workers who formed $22 \%$ and $19 \%$ respectively; $49 \%$ were unskilled; $7 \%$ were professionals.

Among our study subjects, $62 \%$ of them earned an income of about 3000-6000 rupees per month; $17 \%$ of them earned an income less than 3000 per month ; $21 \%$ of them earned an income of more than 6000 per month. In our study it was found that only $10 \%$ of the HIV positive subjects are unmarried (Table.no.3).

Among our study subjects, $99 \%$ of the subjects confessed they had indulged in a sexual intercourse at least once.

Out of the 495 study subjects who had intercourse at least once, $84.8 \%$ of them had an intercourse out of their own interest. Whereas sizeable number of $15.2 \%$ of the study subjects were forced.

Out of the 495 study subjects who had indulged in sexual intercourse, $82.8 \%$ of the subjects had first act of sexual intercourse been 16 to 25 years age group; $14.2 \%$ fell below age 15 years \& $3 \%$ were above 25 years.

In our study, out of 495 study subjects, $62.6 \%$ of the study subjects had their first sexual encounter with their spouse. Sizeable numbers of the study subjects have had their first sexual encounter with a Commercial Sex Worker (19.1\%) and the rest with either friend or relative.

Use of contraceptives was found only among $16.1 \%$ of study subjects who had indulged in sexual intercourse (Table.no.4).

DISCUSSION: In our study out of the 500 subjects, $54 \%$ were male subjects and $46 \%$ were female subjects. On a total, maximum subjects fell between age group 30-39 years. Compared to a similar study in INDIA, $41 \%$ were female subjects and 59\% were male subjects; majority of them fell between age groups 30-34 years ${ }^{6}$. Compared to a similar study done in Goa with only males as the sample, maximum subjects fell between age group 35- 49 years, similar to our study 7 . In another study as well maximum subjects fell between age group 35-49 years ${ }^{4}$.

Illiteracy is one of the major reasons for the rampant increase in the number of HIV positive cases. Out of the 500 subjects taken for our study, $45 \%$ of them were illiterates. Compared to the similar study done, $30 \%$ were illiterate; $24 \%$ had a primary education; $36 \%$ had a high school education \& $10 \%$ had a higher education; whereas in our study there were significantly more number of illiterates and less number of subjects with pre-university education ${ }^{6}$. Compared to the similar study done in Chennai, $30 \%$ were illiterates; $34 \%$ had primary education; $25 \%$ had secondary education \& $11 \%$ were professionals whereas in our study there was significantly more number of illiterates 8 . Compared to another similar study done in south India, $25 \%$ were illiterate; $50 \%$ were educated till high school; $25 \%$ were educated till Pre University, whereas in our study there were significantly more number of illiterates and less number of subjects with high school and pre-university education'.

Ever since the first case of HIV was diagnosed in Chennai in the year 1986, HIV-AIDS was thought to be, primarily, a disease of Commercial Sex Workers and Truck drivers. But in the past decade the infection has crept into the richer sections of the society. In our study, about half of the study subjects were unskilled workers primarily daily wage workers followed by semi skilled and skilled workers. Compared to a study in INDIA, 19\% were unemployed; $81 \%$ 
were employed 6 .Whereas in our study we have a large population who are unemployed. Compared to a study done in Kasturba Medical College Hospital, Mangalore, Karnataka; laborers and hotel workers constituted 19.9\%., housewives constituted $26.97 \%$; beedi rollers, business and semi-skilled professionals constituted a sizeable number. Drivers constituted only $3.08 \%{ }^{10}$. Compared to another study done in Goa, $66.3 \%$ were employed, $15.7 \%$ were unemployed and $18 \%$ are students 7 . Whereas in our study, we have a larger unemployed population.

Poverty is root cause of all the evil in India including the high rates of HIV. Among our study subjects, a maximum number of study subjects earned an income of about 3000-6000 rupees per month (62\%). Compared to a similar study, $15 \%$ are poorest; $15 \%$ were poorer; $3 \%$ were middle class; $32 \%$ were rich; $15 \%$ were richest 6 ; whereas in our study $17 \%$ have a very low income \& there is no question about rich or richest in our study. Compared to other study, $16 \%$ had a low standard of living index; $32 \%$ had a medium standard of living index\& $52 \%$ had a high standard of living index ${ }^{11}$.

Marital status of the patient was known to generally access the sexual behavior among the subjects. Those who are unmarried are assumed to have Pre marital sex whereas those who are married are assumed to either have sex with either their wives or indulge in extra marital sex. In our study, it was found that only $10 \%$ of the HIV positive subjects are unmarried therefore it can be assumed that the pre marital sex leading to HIV is quite low. Compared to a study done in Chennai $55 \%$ are married; $35 \%$ were single; $7 \%$ were separated; $2 \%$ were divorced $^{8}$. Whereas in our study a significant large number of them are married. Compared to a study done in south India, 57\% are married; $43 \%$ were unmarried (43\%) ${ }^{9}$, whereas in our study a significant large no of them are married and less no of them are unmarried. Compared to a study done in Goa, $45.3 \%$ were single and $54.7 \%$ were married 7 . Whereas in our study maximum subjects are married.

Among our study subjects, $99 \%$ of the study subjects confessed they had indulged in a sexual intercourse at least once. . Late adolescent age group is at threat age group; teenage pregnancies are slowly rising as well. Out of 495 subjects, $14 \%$ of the subjects had first act of sexual intercourse before 15 years of age. Compared to a similar study ${ }^{5}$, about $12 \%$ of study subjects had sexual intercourse before 15 years of age, the findings match with our study .

The scenario of Sexual intercourse before marriage which is very common in western countries has shown a rampant shift into our country over the years. Shear inquisitiveness pushes many into this, in our study out of the 495 study subjects who had intercourse at least once, 420 of them had an intercourse out of their own interest(84\%). Whereas sizeable number of the study subjects was forced, $16 \%$ study subjects, it could have been due to peer pressure or rape. Compared to a study done in Government Medical College \& SSG Hospital, Vadodara, which goes by name "Adolescent HIV/AIDS: Issues and challenges"12, 26\% Of the interviewed female sex workers (FSWs), "Devadasi" FSWs (socially accepted FSWs) had initiated sex work at a much younger age (mean 15.7 vs. 21.8 years) due to childhood sexual abuse; the finding is almost similar to our study where $16 \%$ were forced. Compared to a similar study "sexual behavior in India with risk of HIV/AIDS transmission ${ }^{13}$ ", 25\% reported experience of premarital sex out of interest \& 25 per cent of male students in a Delhi school and 28 per cent of male college students in Hyderabad reporting premarital sexual experience.

Heterosexual is the most common mode of transmission worldwide. As such in this study $83 \%$ of seropositive cases accounted for this commonest mode of transmission which is supported by various studies in India as well as other parts of world $14,15,16$.

Journal of Evolution of Medical and Dental Sciences/Volume1/Issue5/November-2012Page-833 
CONCLUSION: Illiteracy and low socio economic status are still remaining as major determinants of HIV and productive age group of life is more commonly affected so strategies for tackling HIV infection in our country should be based on profile of the patients.

\section{REFERENCES:}

1. B Cribier, M P Schmitt, C Le Coz, and E Grosshans. Changes in sexual behaviour of patients attending an HIV testing centre: a prospective study 1988-1994. Genitourin Med. 1996 February; 72(1): 37-42.

2. National AIDS Control Organization. Annual Report. 2008-2009, http://nacoonline.org/upload/Publication/Annual_Report_NACO_2008-09.pdf accesesed on 07/09/2011

3. Quinn TC, Overbaugh J. HIV/AIDS in women: an expanding epidemic. Science. 2005;308(5728):1582-1583.

4. Journal of Urban Health: Bulletin of New York Academy of Medicine, Vol-83, No.4. 2006

5. Coates TJ, Richter L, Caceres C. Behavioural strategies to reduce HIV transmission: how to make them work better. Lancet. 2008 Aug 23;372(9639):669-84.

6. Perkins JM, Khan KT, Subramanian SV (2009) Patterns and Distribution of HIV among Adult Men and Women in India. PLoS ONE 4(5): e5648. doi:10.1371/journal.pone.0005648

7. Vaz FS, Ferreira AM, Kulkarni MS, Motghare DD. Sexual risk behaviors and HIV/AIDS awareness among males in a rural community in Goa. J Commun Dis. 2006 Mar;38(1):74-8.

8. Solomon SS, Celentano DD, Srikrishnan AK, Vasudevan CK, Anand S, Kumar MS, Solomon S, Lucas GM, Mehta SH. Mortality among injection drug users in Chennai, India (2005-2008). AIDS. 2009 May 15;23(8):997-1004.

9. Chandra PS, Satyanarayana VA, Satishchandra P, Satish KS, Kumar M. Do men and women with HIV differ in their quality of life? A study from South India. AIDS Behav. 2009 Feb;13(1):110-7. Epub 2008 Jul 25.

10. S Jayarama, Shaliny Shenoy, B Unnikrishnan, John Ramapuram, and Manjula Rao. Profiles of Attendees in Voluntary Counseling and Testing Centers of a Medical College Hospital in Coastal Karnataka. Indian J Community Med. 2008 January; 33(1): 43-46.

11. An Lwin, Thein Z., "An Examination of the Association between HIV Related Knowledge, Attitudes, and Behaviors and HIV Infection Status in Five High HIV Prevalence States in India." (2011).Public Health Theses. Paper 168. http://digitalarchive.gsu.edu/iph_theses/168

12. Smriti Naswa and Y. S. Marfatia. Adolescent HIV/AIDS: Issues and challenges. Indian J Sex Transm Dis. 2010 Jan-Jun; 31(1): 1-10.

13. Moni Nag. Sexual behaviour in India with risk of HIV/AIDS transmission. Health Transition Review, Supplement to Volume 5, 1995, 293-305.

14. Verma S, Mahajan A, Singh JB, Sharma M. Clinical Profile of HIV/AIDS patients in Jammu. JK Practitioner. 2007; 14(2):79-83.

15. Destura RV, Berba RP, Mendoza MT et al. Profile of HIV/AIDS Patients at the Philippine General Hospital: Revisting 9 years of Clinical Experience. Philippine journal of Microbiology and Infectious Diseases. 2003; 32:111-21.

16. Khopkar U, Raj S, Sukthankar A, Kulka. Clinical profile of HIV Infection. Indian J Dermatol Ven. 1992; 58(3):155-158. 
Table 1: Age sex wise distribution of study subjects

\begin{tabular}{|c|c|c|c|}
\hline Age group & Male & Female & Total \\
\hline $20-29$ years & $60(22.3 \%)$ & $100(43.6 \%)$ & $160(32 \%)$ \\
\hline $30-39$ years & $110(40.8 \%)$ & $85(36.9 \%)$ & $195(39 \%)$ \\
\hline $40-49$ years & $80(29.6 \%)$ & $45(19.5 \%)$ & $125(25 \%)$ \\
\hline $50-59$ years & $15(05.5 \%)$ & 00 & $15(03 \%)$ \\
\hline$>59$ years & $05(01.8 \%)$ & 00 & $05(01 \%)$ \\
\hline Total & $270(100 \%)$ & $230(100 \%)$ & $500(100 \%)$ \\
\hline
\end{tabular}

Table 2: Mode of Transmission of HIV among study subjects

\begin{tabular}{|c|c|c|}
\hline Mode of Transmission & Frequency & Percentage \\
\hline Heterosexual & 415 & $83.00 \%$ \\
\hline Blood transfusion & 002 & $00.40 \%$ \\
\hline Inject able drug abuse & 001 & $00.20 \%$ \\
\hline Don't know & 082 & $16.40 \%$ \\
\hline Total & 500 & $100 \%$ \\
\hline
\end{tabular}


Table 3: Socio demographic characters of study subjects

\begin{tabular}{|c|c|c|}
\hline Socio demographic characters & Frequency & Percentage \\
\hline Education & 225 & $45.0 \%$ \\
Illiterate & 215 & $43.0 \%$ \\
Primary & 045 & $09.0 \%$ \\
High school & 010 & $02.0 \%$ \\
Pre university & 005 & $01.0 \%$ \\
Degree \& above & 245 & \\
Occupation & 110 & $22.0 \%$ \\
Unskilled & 095 & $19.0 \%$ \\
Semiskilled & 015 & $03.0 \%$ \\
Skilled & 035 & $07.0 \%$ \\
Professional & & \\
Business \& others & 085 & $17.0 \%$ \\
\hline Income (monthly) & 310 & $62.0 \%$ \\
<3000 Rs & 105 & $21.0 \%$ \\
\hline 3000 - 6000 Rs & & \\
$>6000$ Rs & 450 & $90.0 \%$ \\
\hline Marital status & 050 & $10.0 \%$ \\
Married &
\end{tabular}

Table 4: Distribution of study subjects based on sexual behavior

\begin{tabular}{|c|c|c|}
\hline Sexual behaviors & Frequency & Percentage \\
\hline Ever indulged in sex? & 495 & $99.0 \%$ \\
Yes & 005 & $01.0 \%$ \\
No & & \\
\hline Age at first act of sex & 070 & $14.2 \%$ \\
$<15$ years & 410 & $82.8 \%$ \\
$15-25$ years & 020 & $03.0 \%$ \\
>25 years & & \\
First time sex with & 310 & $62.6 \%$ \\
Spouse & 020 & $04.0 \%$ \\
Relative & 075 & $15.3 \%$ \\
Friend & 095 & $19.1 \%$ \\
\hline Commercial sex worker & & \\
Sex before marriage & 420 & $84.8 \%$ \\
Out of interest & 075 & $15.2 \%$ \\
Out of force & & $16.1 \%$ \\
Use of contraception & 080 & $83.9 \%$ \\
\hline Yes & 415 & \\
No & & \\
\hline
\end{tabular}

